\title{
Understanding sleep among couples: gender and the social patterning of sleep maintenance among younger and older couples
}

\author{
Robert Meadows \\ r.meadows@surrey.ac.uk \\ Sara Arber \\ Department of Sociology, Faculty of Arts and Human Sciences, University of Surrey
}

(Received May 2011 Revised December 2011)

\section{Abstract}

Sleep, which is vital for health and wellbeing, is influenced by a complex array of (neuro)biological and social factors. Previous research has suggested that these factors vary across the life course, as well as being affected by transitions, such as parenthood, care-giving and widowhood. This research has also suggested that many of these transitions have a greater affect on women's sleep. Yet much of this research has focused on women and one-sided reports of partner behaviours. This paper draws on data from Wave 1 of the Understanding Society Survey to examine gender differences in sleep maintenance within younger and older heterosexual couples. Data were collected in 2009 from a representative sample of households in Britain with a response rate of $59 \%$. Sleep maintenance, namely waking on 3 or more nights per week, was included in a self-completion module. A series of logistic regression models are run using sleep maintenance as a dependent variable; i) a two level model for couples where the male is aged 50 or less ( $n=2452$ couples); ii) a two level model for older couples where the male is aged above 50 ( $n=1972$ couples); iii) bivariate models which allow for odds to be calculated separately for male and female partners. Results from the couple level models illustrate how both younger and older women have increased odds of difficulties with sleep maintenance (as compared to their male partners). Poor sleep maintenance is also associated with poor health, own unemployment, dissatisfaction with income, having had a previous cohabiting relationship and having younger children for both men and women. Reports by the husband of frequency of coughing/snoring at night is significantly associated with their wives' sleep maintenance among younger couples and vice versa; but among older couples there is only a significant association of husband's snoring on wife's sleep. Whilst the current analysis is cross-sectional, further understanding of the dynamic relationships of sleep will be revealed through longitudinal analysis as Understanding Society moves through future waves.

\section{Introduction}

Sleep is vital for health and wellbeing. As Marmot (2010) suggests, too little or too much of it is a 'cause' of ill health and a 'symptom' of certain disorders. It is now widely reported that quantity and quality of sleep are predictors of type 2 diabetes and that a decrease (or increase) in sleep duration affects all-cause mortality (Cappuccio and
Miller 2010). Sleep disturbance is also embedded within discussions of depression; with the former included in diagnostic criteria for the latter (Weich 2010). As well as being a 'cause' and 'symptom', poor sleep is considered to be 'consequence' of $21^{\text {st }}$ century western worlds. At the same time as being told that sleep is the ultimate performance 
enhancer, it is also claimed that there exists a 'macho culture of sleeplessness' (Appleyard 2002) and that we live "in an incessant or unremitting society, which has steadily 'colonized' night in a variety of ways, from the humble electric light bulb, to shift-work, night-clubs, 24 hour television and convenience stores" (Williams and Boden 2004).

The link between sleep and health is influenced by a complex array of (neuro)biological and social factors. As we discuss in the next section of this paper, there are strong indications that these factors vary across the life course, as well as being affected by transitions, such as parenthood, caregiving and widowhood (Williams et al 2010). Further to this, sleep for most adults is a dyadic experience, yet there has been little quantitative (survey) analysis to examine the effects of partner behaviours on each others' sleep; nor how these couple effects vary across the trajectory of the couple relationship.

\section{Couples and sleep across the life course}

Within their discussion of sleep and ageing, Hislop and Arber (2006) propose 'four key temporal dynamics' for studying sleep and ageing, comprising: i) Biological or physical ageing; ii) Institutional structures, such as engagement with paid work or education; iii) Relational structures, such as those associated with the individual's roles and relationships with partners and children; and iv) Biographical transitions, such as those associated with marriage, parenthood and retirement.

The first suggested 'temporal dynamic' is noncontentious. The deterioration of sleep quantity and quality is largely considered to be a part of 'normal' ageing. Older people spend much less time in slow wave sleep (Bliwise 2005; Whalley 2001). The suprachiasmatic nucleus has also been shown to deteriorate with ageing and contribute to detrimental changes in circadian rhythms (Dijk et al 2000). These processes intersect with an increased prevalence of chronic ill-health, disability and impairment which can all cause pain and discomfort at night adversely affecting sleep (Vitiello et al 2002).

The remaining temporal dynamics have also been shown to be salient when considering the health/sleep nexus. The 'institutional structure' of employment can negatively impact on an individual's sleep quality and quantity. In 1986, 26 per cent of men and 18 per cent of women in the US labour force reported working variable shifts
(Gordon et al 1986). In 2001, approximately one in five workers in Europe were employed on shift patterns involving night work (Harrington 2001). Those working shifts are more likely to complain of fatigue, anxiety and report a reduction in quality and quantity of sleep (Harrington 2001). Further to this, punishing work schedules and the accompanying stresses can impact negatively upon sleep even where individuals work 'normal' hours. Thus, Linton (2004) found that stress in the form of 'poor' psychosocial work environment increased the risk of sleep problems. Somewhat similarly, Akerstedt et al (2002) identify how high work demands and physical effort at work are risk indicators for disturbed sleep, and Cropley et al (2006) illustrate how teachers with high job strain report poorer quality sleep (see Williams 2005 for a discussion of how the prevalence of sleep problems may vary by occupation). Unemployment is also associated with poor sleep. As Arber et al (2009) report, the unemployed have significantly elevated odds of reporting sleep problems, even after controlling for worries, smoking, depression, health and a range of socio-economic factors.

Retirement and the biographical transitions which accompany retirement do not necessarily remove the link between work and sleep quality. Henry et al (2008) conducted interviews with 24 patients ( 19 female and 5 male) who were receiving treatment for insomnia. They found that patient explanatory models of insomnia revolved around 'work'. Work was offered as the primary causal agent in the development of insomnia, the primary reason for needing good sleep, the reason for seeking medical help and the reason why individuals complied with medical regimens. As the authors identify "even retired informants couched their illness experience in terms of work, further evidencing the powerful internalizing role of labor in experiences of insomnia, and the long-term impact of contemporary working lifestyles on sleep" (Henry et al 2008: 724). Lallukka et al (2010) also found that prior economic difficulties in childhood remain associated with insomnia even into adulthood.

Gender underpins all aspects of Hislop and Arber's (2006) model of how 'temporal dynamics' impact on sleep. In their qualitative study of midlife women's sleep, Hislop and Arber (2003) found that women prioritise their partner's and children's sleep above their own. The interaction of the 
physical and emotional labour involved in caring for babies, young children and teenagers, and the worries and concerns associated with family responsibilities, work, and caring for ageing parents, are said to compromise women's access to quality sleep and in particular their sleep maintenance. From this, Hislop and Arber conclude that being "female within a family structure can thus be synonymous with a loss of [fundamental human] sleeping rights" (Hislop and Arber 2003). Similarly, Venn et al's (2008) qualitative study of working age couples found that women undertake a 'fourth shift' of night time care for children, while prioritising their partners' sleep.

Implicit within Hislop and Arber's (2006) model is also the idea that the couple relationship is an additional temporal dynamic for many. Most adults share their sleeping space with a partner and there are normative conventions requiring couples to sleep in the same bed. As Venn (2007) notes in her discussion of snoring:

"The integrity of the couple relationship is also at risk when, because of snoring, couples relocate to a different bed or bedroom, so that both husbands and wives felt the need to assert that relocation was a last resort, and not something either wanted to do."

The strength of this normative convention appears to change over the life course of the individual and the couple relationship. Older women have been shown to be more able to embrace behaviours that challenge these conventional norms and relocate to another bedroom (Hislop and Arber 2006). Hislop and Arber (2006) report that $28 \%$ of partnered women aged over 60 sleep separately from their husbands, compared to only $7 \%$ in their late forties or fifties. Similarly, the impact of snoring within a couple can change over time. At the beginning of a relationship, couples are said to be more alert to the embarrassment that accompanies burping, snoring or farting in bed, yet as the relationship develops couples learn to 'fit together', and to 'mutually adapt' (Meadows et al 2008).

Partners come together with their own notions of what is normative regarding sleeping behaviours of themselves and their partners. These are influenced by at least two things: (prior) knowledge of others' sleep, and clear notions of what makes sleeping bodies 'unattractive' (such as farting, snoring). The longer the duration of the relationship, the greater the potential that couples 'routinize' their experience of each other. This may be via an 'acceptance', an emphasis on 'mutual inconsideration', 'normalization' or the 'neutralizing' of potentially embarrassing events (Meadows et al 2008).

Much of the work cited above has focused on sole reports from women and has been qualitative rather than based on representative surveys of men and women, with very few studies of couples. The present paper explores the associations between sleep maintenance and gender, health, socioeconomic status and a range of relational variables (such as partner snoring) - using data from both men and women within the same couples, and examines different subsets of couples (younger and older). The paper examines the following research questions i) does the magnitude of gender differences in sleep maintenance differ between younger and older couples?; and ii) do social factors, such as presence of a child, employment status, partner behaviours such as partner's snoring, impact on men and women's sleep maintenance differentially? Whilst the analysis presented here is necessarily cross-sectional, as it moves through future waves Understanding Society will provide a unique source of data which will enable the relationship between temporal dynamics (including the couple relationship) and changes in sleep over time to be fully explored.

\section{Methodology}

This paper draws upon data from the first year of Wave 1 of the new Understanding Society survey. Data were collected in 2009 from a representative sample of households in Britain, with a response rate of $59 \%$, resulting in an interviewed sample of 14,065 households and 22,265 individuals aged 18 and over (McFall and Garrington 2011; Table 1a below). The Understanding Society survey included 7 questions on sleep quality/quantity, as well as a range of socio-economic and demographic questions and modules on marital and cohabitation history. The sleep questions, and the response categories, mirror some aspects of the clinically validated Pittsburgh Sleep Quality Index (Buysse et al 1989). There are also similarities to the Jenkins Sleep Questionnaire (Jenkins et al 1988), which asks whether individuals have experienced trouble falling asleep, trouble staying awake, waking up at night, and waking up feeling tired. 
The paper focuses on sleep maintenance; that is how often the respondent reported they 'had trouble sleeping during the past month because they wake up in the middle of the night or early in the morning?' Our focus on self-reported nocturnal awakenings reflects the attempt to capture aspects of sleep which have been suggested to be gendered (for example, nocturnal child care, partner disturbances through snoring, work stresses). Data was collected using self-completion response categories which ranged from 'Not during the past month' to 'More than once most nights'. A dichotomised variable was created which identified those who experienced awakenings less than 3 nights per week (0) and those who experience awakenings on ' 3 or more nights' per week (1). This recoding reflects DSM-IV-TR criteria which define a sleep problem as one which is present for 3 or more nights per week for at least 1 month (Lallukka et al 2011).

\section{Table 1. Number of individuals within the whole sample and analysis subsample of couples}

\section{(a) Numbers for Individuals on sleep items for whole sample}

(b)

\begin{tabular}{l|l} 
No. of interviews (aged 18+) & 22,265 individuals within 14,065 households \\
\hline $\begin{array}{l}\text { No. of individuals responding to sleep module } \\
\text { No. of individuals responding to 'sleep } \\
\text { maintenance' item }\end{array}$ & $\begin{array}{l}19,694 \text { individuals (11.5\% unit non-response) } \\
18,388 \text { individuals (6.6\% of unit respondents had } \\
\text { item non-response) }\end{array}$ \\
$\begin{array}{l}\text { No. of individuals responding to 'wakes self } \\
\text { through snoring/coughing/ item }\end{array}$ & $\begin{array}{l}16,407 \text { individuals (16.7\% of unit respondents had } \\
\text { item non-response) }\end{array}$
\end{tabular}

\section{(b) Analysis sub-sample of couples}

No. individuals interviewed who indicate that they are living with a spouse/partner or living as a couple

No. of individuals where both partners in couple were interviewed

No. of individuals where both partners in Heterosexual couple were interviewed

No. of individuals in heterosexual couples who answered 'sleep maintenance' item

No. where both partners in heterosexual couples answered 'sleep maintenance' item

No. of individuals in 4,424 heterosexual couples who answered 'wakes self through coughing/snoring' item

As the main concern of this paper is to examine gender within couples, the present analysis is restricted to a specific sub-group of respondents heterosexual couples where data exists for both partners. Individuals who identified that they were
13,975 individuals

11,306 individuals within 5,653 couples

11,208 individuals within 5,604 couples

9,615 individuals within 5,175 couples

8,848 individuals within 4424 couples

7,925 (10\% item non response in this sub-sample)

living with a spouse ( $n=11,263)$, or living as a couple $(n=2,712)$, were identified. A further step then identified those where data was available from both partners in a couple, and a unique identifier was given to each dyad ( $n=5,653$ couples). Further steps 
then identified couples where both partners within heterosexual couples had given an answer for the dependent variable ( $n=4,424$ couples; see table $1 b)$.

Models were run separately for those couples where the male was aged 50 and under $(n=2,452$ couples) and those couples where the male was aged over 50 ( $n=1,972$ couples). There is obvious potential for multi-collinearity when examining predictors which involve 'time' in a cross-sectional analysis. We would expect factors such as length of relationship, marital status, and number of divorces to be affected by increasing age. Within the present dataset, there is a close association between age of individuals and length of current partner relationship (correlation coefficient of $0.862 ; p<0.001)$. There is also, an expected, close association between age, marital status and length of relationship. The decision to separate the age groupings at 50 reflects earlier research which suggests qualitative difference between these two age groups related to childcare responsibilities and causes of poor sleep. Williams et al (2010), for example, note in their analysis of the Psychiatric Morbidity Survey 2000, that up to age 50 'worries' is by far the most frequently cited cause of sleep problems. However, later in life, 'worries' are surpassed by 'illness/discomfort' as the primary reason. As noted above, later life is also accompanied by transitions in employment and childcare responsibilities; and separate models enable these variables to be adapted accordingly. The decision to select the male age was somewhat arbitrary, as partners tended to be of similar age (mean age difference, 4.7 years, SD 4.8 years), but reflected the fact that men were older in $68 \%$ of the partnerships.

\section{Analysis Approach}

Standard correlation analysis techniques are often applied to data on couples (Kenny and Cook 1999), in which sleep data is aggregated to give an average score for each individual within the couple. Each spouse's aggregated score would then be correlated with their partner's aggregated score. With heterosexual dyads these techniques quantify the extent to which women who receive a high score on a variable, relative to other women, are matched with men who receive a high score, relative to other men. However, this aggregation may result in cross-level errors or level of analysis errors (Gonzalez and Griffin 1997).

Within the present study, multilevel models were utilised and analysis proceeded in the following steps. First, two level (individuals nested within couples) logistic regression models were created, for each age group: which included 'gender' and the further independent variables identified below. $1^{\text {st }}$ order marginal quasi-likelihood (MQL) estimates were then used as the starting point for second order predictive quasi-likelihood (PQL) estimates (Rasbash et al 2005)'. The proportion of variance at the couple level was calculated using the linear threshold method; with the individual level variance considered to be $\pi^{2} / 3$.

Figure 1. Multilevel logistic model

$$
\log \left(\frac{\pi_{i j}}{1-\pi_{i j}}\right)=\beta_{0}+\beta_{1} x_{i j}+u_{j}
$$

Secondly, a model was fitted that allowed for separate outcome measures for men and women within couples. This model is thus a bivariate single level logistic model and allows for a correlation between men and women which is reported in
Tables 3 and 4 and is equivalent to the proportion of the total variance that is between couples in the 2-level model described above. We report the odds ratios for men and women and the correlation between male and female nocturnal awakenings.

Figure 2. Bivariate Logistic model for a single predictor

$$
\begin{gathered}
\log \left[\frac{\pi_{1 j}}{1-\pi_{1 j}}\right]=\beta_{01} z_{1 i j}+\beta_{11} z_{1 i j} x_{i j} \\
\log \left[\frac{\pi_{2 j}}{1-\pi_{2 j}}\right]=\beta_{02}\left(1-z_{1 i j}\right)+\beta_{12}\left(1-z_{1 i j}\right) x_{i j}
\end{gathered}
$$

$z_{1 i j}=1$ if male, 0 if female 


\section{Variables in the models}

As one aim of this paper is to explore gender differences, variables were selected based on substantive findings from earlier studies and there was not a concern with creating the most parsimonious model. Within models for age 50 and under, individual level variables include 'gender'; 'age'; 'highest educational qualification' (recoded into categories (0) degree or above, (1) nursing and professional, A level equivalents, (2) General Certificate of Secondary Education (GCSE) or lower, (3) none); health (SF-12 subjective general health); employment status (coded as (0) employed or selfemployed, (1) retired/unemployed, (2) on maternity leave or looking after the family); satisfaction with income (recoding the original scale to identify those who are dissatisfied compared with those who are satisfied or neutral); and whether they had experienced a previous cohabiting relationships (coded into 0 for 'no' and 1 for 'yes') ii.

Couple level variables include whether a child aged under 2 is present in the household (to measure impact of young children on sleep) and 'possible spare room'. This latter variable was created in an attempt to proximate bedsharing. It was calculated as number of bedrooms-(number of people in the household-1) and based on assumptions that couples will normatively share a room (see Hislop 2007), that other adults in the household would be given their own room, and that children would be given a room each if there was space. Thus, a couple with two children, living in a household with three bedrooms would have 0 spare rooms.

A partner impact variable was also developed which identified whether the partner reported waking because of their own coughing or snoring. Each respondent was asked whether they had trouble sleeping because they 'cough or snore loudly in the last month' ${ }^{\prime i i i}$. As noted in Table 1, 923 individuals within the analysis sample of 4,424 couples did not answer this item. Whilst the selfcompletion design does not allow us to distinguish between forms of non-response, we do suggest that there is a strong case for considering this item nonresponse as synonymous with 'don't know'. This is principally for two reasons: first, within the analysis sample there is minimal non-response for the other sleep items and all but nine respondents answered the sleep quality item. This would suggest that nonresponse on the 'cough or snore' item is not linked to satisficing behaviour and that there is something specific about the 'snore/cough' question. Second, we know from previous qualitative research, that respondents from 'normal' populations often suggest that they 'do not know' whether they cough or snore at night. In studies of couples, individuals often look to their bed partner to answer this question for them (see Venn 2007 for examples). A similar difficulty can be found within clinical populations. Obstructive sleep apnoea which is linked to snoring and micro arousals - is often said to remain under-diagnosed because the patient is unable to remember the "active state of the disease" during sleep (apneos.com 2003).

For the models for age over 50, several variables were altered to map onto the changes that accompany mid- and later-life. As a higher proportion of couples aged over 50 were retired, employment was coded into 2 categories ('employed' or 'not employed'). Similarly, the children variable was adapted to become 'child of any age in the household'.

\section{Results}

Table 2 shows the gender and age group distributions of the variables used in the models; and the proportion of men and women within each category reporting sleep maintenance problems on 3 or nights per week. 
Table 2. Descriptive statistics: \% of men and women in 4,424 heterosexual couples reporting sleep maintenance problems by age group

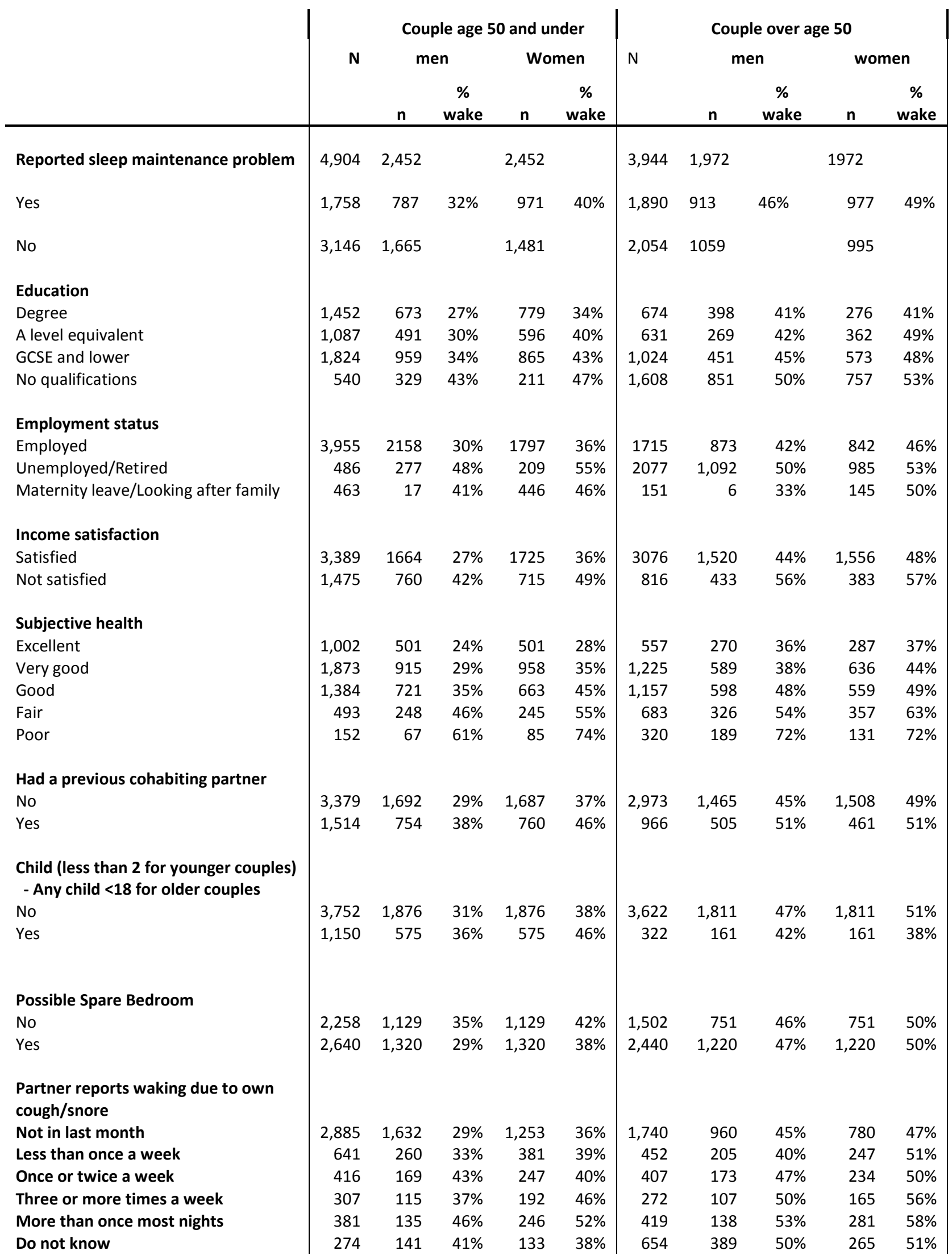


In younger couples (where the male is aged 50 or under, $n=4,904$ individuals within 2,452 couples in the models), the average duration of the couple relationship was 10.5 years (SD 7.49) and 32\% of men and $40 \%$ of women reported sleep maintenance problems on ' 3 or more nights' per week' within the last month.

The multilevel logistic regression analysis of younger couples (age 50 and under) in Table 3 shows that women have higher odds of reporting sleep problems (OR 1.38). Within the couple model, individuals who are unemployed or retired $(O R=1.51)$ and those dissatisfied with their income $(O R=1.47)$ are more likely to have sleep maintenance problems. A health gradient is also strongly evident, with those reporting poor health having an odds ratio of 4.02 compared to those reporting excellent health. As expected, the presence of a child under 2 years of age also increases the odds of poor sleep maintenance $(O R=1.49)$. The presence of a partner who reports trouble sleeping because of coughing or snoring is strongly associated with their partner's sleep maintenance; this reveals an odds ratio of 1.72 where their partner reports loud cough/snoring more than once on most nights. The proportion of variance which remains at the couple level is $2 \%$. 
Table 3. Odds ratios for sleep maintenance for couples where the male is aged 50 or less (shading indicates significance at $p<0.05$ ), $n=2,452$ couples

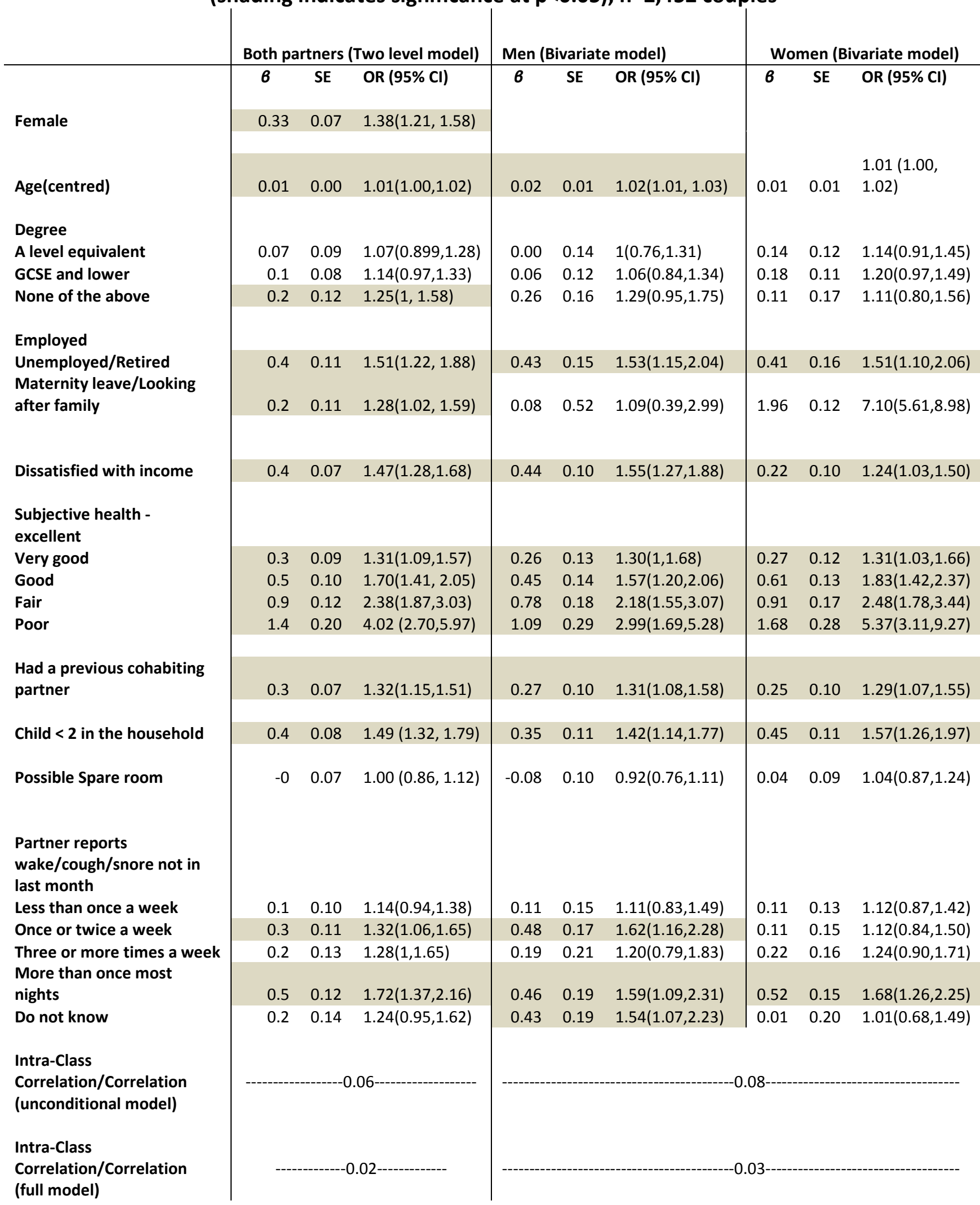


Table 4. Odds ratios for sleep maintenance for couples where the male is aged over $\mathbf{5 0}$ (shading indicates significance at $p<0.05), n=1,972$ couples

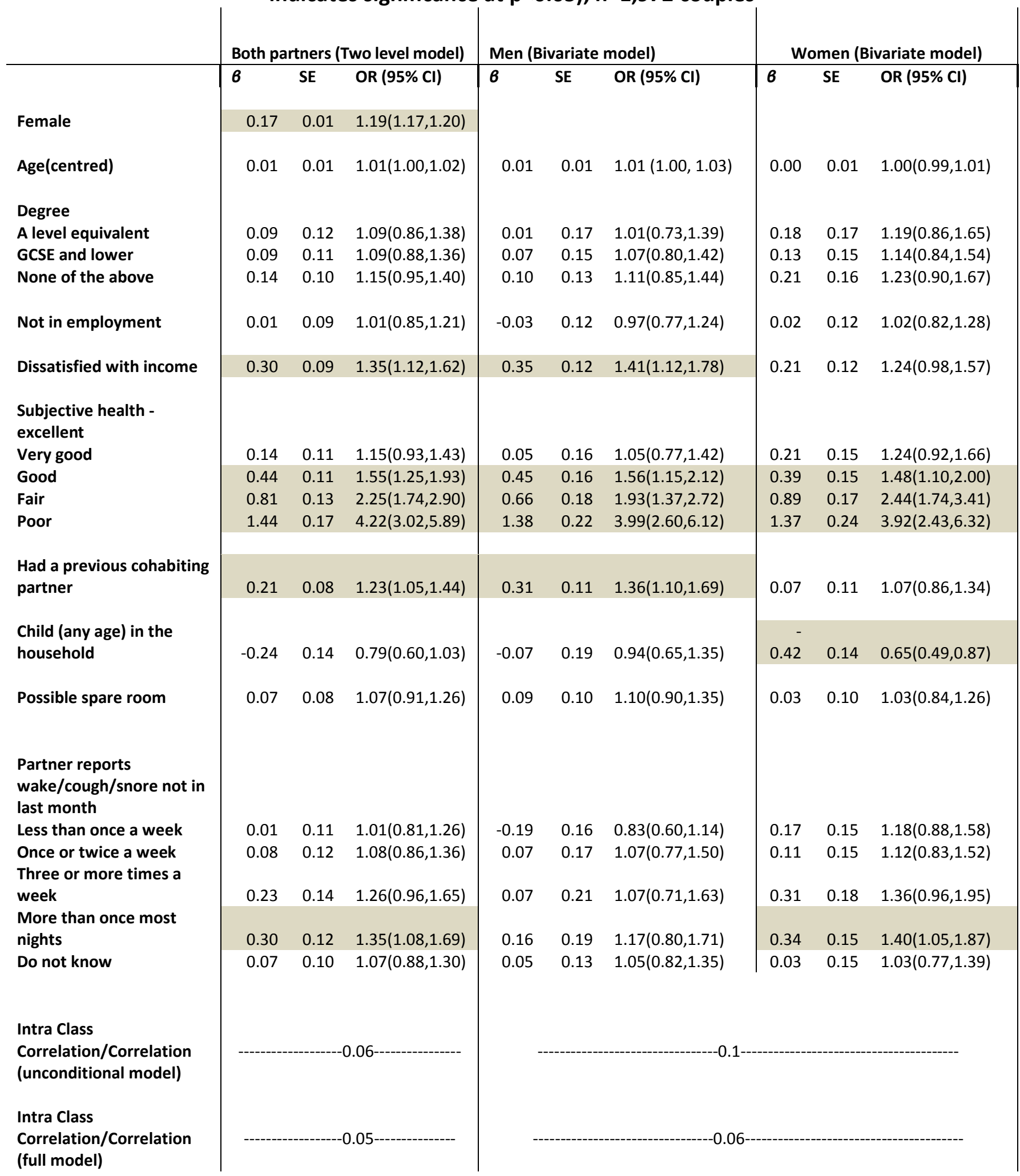

Comparing the findings noted above with findings from analysis of couples aged over 50 suggests some prima facie differences (Table 4).
Among the 3,944 individuals within 1,972 older couples, relationships have lasted for an average of 34.9 years (SD 14.1) and there is a much higher 
prevalence of problems maintaining sleep (with $46 \%$ of men and $49 \%$ of women reporting difficulty on 3 or more nights a week, Table 2). We would expect the prevalence to be higher in the older couples. In a clinical sense, this question positions closely to the idea of 'sleep maintenance insomnia' which is more prevalent in older couples.

Whilst the gender effect appears smaller in this age group, women continue to have higher odds of sleep maintenance problems (OR=1.19). Among older couples, education, and satisfaction with income and health are associated with greater sleep problems. Those dissatisfied with income $(O R=1.35)$ and in poor health $(O R=4.2)$ report frequent sleep maintenance problems. The association between sleep maintenance problems and previous cohabitation $(O R=1.23)$ also remains within the older age group; as does the impact of a partner who reports nightly snoring/coughing $(O R=1.35)$. The proportion of variance which remains at the couple level is $5 \%$.

When bivariate models are run to obtain estimates for husbands and wives separately within younger couples (columns 2 and 3 in Table 3 ), the correlation between male and female reported sleep maintenance is 0.08 . This reduces to 0.03 when the social factors are entered into the model. In essence, within the younger couples both men and women are affected by the same factors although there are stronger effects for men for satisfaction with income, and higher odds for women with a child less than 2 years of age in the household.

When models are run which enable estimates to be obtained for older husbands and wives separately (columns 2 and 3 in Table 4), the correlation between male and female reported sleep maintenance is 0.1 . This only reduces to 0.06 when the social factors are entered into the model. It can be seen that whilst health remains important for both partners, men have higher odds of poor sleep maintenance if they are dissatisfied with income (Men OR=1.41; Women not significant) or have experienced a previous cohabitation (Men $\mathrm{OR}=1.36$; Women not significant). For women, having a partner who reports waking through coughing/snoring more than once most nights $(O R=1.40)$ is strongly associated with poor sleep maintenance; but there is no significant effect of wives' snoring on their husband's sleep maintenance.
With respect to our research questions, the above findings suggest that, firstly, gender differences in problems in sleep maintenance are greater in younger couples. Formal tests confirm a significant interaction between gender and age; with the effect of being 65 and over significantly altering between men and women ( $6-0.373$; s.e. 0.145 ). Secondly, with younger couples the same social factors entered into the models, impact on both husband and wives sleep - although to different magnitudes, whereas among older couples, men's and women's sleep becomes both more similar in terms of sleep maintenance problems, and more 'differentiated' with, for example, women's sleep maintenance more likely to be associated with their partner's snoring.

\section{Discussion and conclusions}

This paper has reported findings from analysis of younger (aged 50 and below) and older (aged over 50) couples. Many of the findings confirm earlier research showing the poorer sleep of women and the relationship between poor sleep and socio-economic status and health. Those with no educational qualifications, those in poor health and those dissatisfied with their income are also more likely to report problems with sleep maintenance.

The present study also reported novel findings from quantitative data on the associations of young children in the household, previous cohabitating partnerships and partners' snoring on both men and women's sleep - especially in younger couples. Whilst there is now a wealth of understanding which demonstrates strong bi-directional links between both sleep quality and quantity and a range of chronic and acute illnesses, much of this research ignores the fact that many individuals exist within dyads. Examining data from both partners within a couple sits more comfortably with theoretical notions that 'gender' is relational, and provides a more detailed examination of the role that marriage/marital status may play in health status. Within this paper, two key claims are made with respect to gender. First, in younger couples, whilst women report greater sleep problems, both men and women's sleep maintenance shows associations with a wide range of social factors entered into the model and with the frequency of their partners' snoring. Second, the gender dynamic within couples does interact with age, and within older couples, women's sleep maintenance 
appears more likely than men's to be associated with their partners' snoring/coughing.

These findings add to previous research on gender and sleep. Venn et al (2008), for example, used qualitative interview data from 26 healthy, heterosexual couples with children, to illustrate how physical and emotional care for young children at night was largely provided by women, disturbing women's own sleep. In particular, there was a lack of explicit negotiation between partners about who provided this care, with mostly tacit understandings that women would get up in the night to deal with, for example, nappy changing or settling anxious children. Even when women returned to employment or fulltime education, they continued to undertake most of the child care at night. Whilst this may certainly be the case, findings from the present analysis suggest that husbands' selfreported sleep maintenance is also associated with the presence of a young child. Similarly, Arber et al (2007), used survey data to show that women's subjective sleep quality was primarily influenced by how their partners slept, how their children slept, and their own worries. Within the present study, an association is found between sleep maintenance and partner reports of coughing/snoring for both men and women ${ }^{\mathrm{iv}}$.

Results from the present analysis also suggest that temporal dynamics exist in sleep maintenance. Following Hislop and Arber (2006), our analysis confirms the impact of biological or physical ageing (age and health status), institutional structures (employment), relational structures (presence of a child less than 2 and partner reports of snoring) and biographical transitions (impact of previous cohabitation). Results also suggest a temporal dynamic to the couple relationship; with the relationship between gender and sleep maintenance altering by age and with older women's sleep associated more with her partners' reports of his own snoring.

However, this analysis is limited by the fact that Understanding Society presently only allows for cross-sectional analysis of sleep. The true potential Understanding Society offers will be realised in future waves. The present analysis has also purposefully focused on a specific subset of Understanding Society; and couples where both partners complete the survey may be atypical. We would suggest that two particular lines of analysis will become especially valuable in future waves. First, analysis can fully explore the way that gender impacts on sleep quality and quantity within couples and how this may change over time. Second, as Understanding Society also contains questions about relationship satisfaction, prospective analysis will be able to explore the associations between sleep, health and changes in marital relationships in greater depth.

Recent literature suggests that married individuals report fewer sleep problems than their unmarried counterparts (Arber et al 2009). Troxel et al (2009) found that maritally happy women report fewer sleep disturbances; whilst Troxel et al (2010) suggested that there are sleep advantages for women who have a stable relationship history, as opposed to those who had lost or gained a partner over the same period. Drawing on longitudinal data from mid-life women, Troxel et al (2010) identified those women who were married/living as married at baseline, and those who were not, and traced them across 8 years, creating categories 'consistently married', 'consistently unmarried', 'lost a partner' and 'gained a partner'. Cross-sectional analysis comparing 'married' with 'unmarried' women found that currently being married was associated with better sleep, but that this was only in unadjusted models. Marital trajectories were important, however, with 'consistently married' women showing a relative advantage in sleep quality and quantity as compared to the other groups. As Hale (2010) suggests, whilst Troxel et al's findings do not suggest causality, they hint towards part of the explanation for the enduring positive association between marital status and health. As both Hale (2010) and Troxel et al (2010) note, however, there is a need to explore this further using different subpopulations (which include men) and to examine relationship satisfaction concurrently. There is also much that can be gained by analysing differences within those who are currently married/cohabiting and the underlying qualitative dimensions of high quality marital relationships (Troxel et al 2010). 


\section{Acknowledgements}

The authors would like to thank Dr lan Brunton-Smith for comments on an earlier draft and for several detailed statistical pointers and references. The authors also acknowledge the SomnIA (Sleep in Ageing) project, which is funded by the New Dynamics of Aging initiative, a multi-disciplinary research programme supported by AHRC, BBSRC, EPSRC, ESRC and MRC (RES-339-25-0009). We are also grateful for the insightful comments from the reviewers and editor.

\section{References}

Akersted T, Knutsson A, Westerholm P, Theorell T, Alfredsson L and Kecklund G. (2002) Sleep disturbances, work stress and work hours. A cross-sectional study. Journal of Psychosomatic Research, 53, 741748.

Apneos.com (2003) Sleep apnea is under diagnosed, http://www.apneos.com/underdx.html (accessed $02 / 12 / 2011)$

Appleyard B. (2002) Night waves. New Statesman, (accessed $16^{\text {th }}$ April 2007)

Arber S, Hislop J, Bote M and Meadows R. (2007) Gender roles and women's sleep in mid and later life: a quantitative approach. Sociological Research Online, 12(5). Retrieved December 10, 2008, from http://www.socresonline.org.uk/12/5/3.html

Arber S, Bote M and Meadows R. (2009) Gender and the socio-economic patterning of self-reported sleep problems in Britain. Social Science and Medicine, 68, 281-289.

Arber S and Meadows R. (2011) Social and health patterning of sleep quality and duration. In S McFall and N Garrington. eds. Understanding Society: Early findings from the first wave of the UK's Household Survey. Pp 87-98. Institute for Social Research, Colchester, Essex.

Bliwise DL. (2005) Normal aging. In MH Kryger, T Roth and WC Dement. eds. Principles and Practice of Sleep Medicine. Pp 24-38. Elsevier Saunders, Philadelphia.

Borbely A. (1986) The secrets of sleep. Longman Scientific and Technical, London.

Buysse DJ, Reynolds CF, Monk TH, Buman SR and Kupfer DJ. (1989) Pittsburgh Sleep Quality Index: a new instrument for psychiatric practice and research. Journal of Psychiatric Research, 28, 193-213.

Cappucio FP and Miller MA. (2010) The epidemiology of sleep and cardiovascular risk and disease. In F Cappaccio, M Miller and S Lockley. eds. Sleep Epidemiology. Pp 83-110. Oxford University Press, Oxford.

Cropley M, Dijk D-J and Stanley N. (2006) Job strain, work rumination and sleep in school teachers. European Journal of Work and Organizational Psychology, 15, 181-196.

Dijk D-J, Duffy JF and Czeisler CA. (2000) Contribution of circadian physiology and sleep homeostasis to agerelated changes in human sleep. Chronobiology International, 17, 285-311.

Gonzalez R and Griffin D. (1997) The statistics of interdependence: Treating dyadic data with respect. In SW Duck. ed. Handbook of Personal Relationships: Theory, Research, and Interventions. 2nd Ed. Pp 181213. Wiley, Chichester.

Gordon NP, Cleary PD, Parkey CE and Czeisler CA. (1986) The prevalence and health impact of shiftwork. American Journal of Public Health, 76, 1225-1228.

Hale L. (2010) Sleep as a Mechanism through which Social Relationships Affect Health; Commentary on Troxel et al, Marital/Cohabitation status and history in relation to sleep in midlife women. Sleep, 33, 862-3.

Harrington JM. (2001) Health effects of shift work and extended hours of work. Journal of Occupational and Environmental Medicine, 58, 68-72.

Henry D, McClellen D, Rosenthal L, Dedrick D and Gosdin M. (2008) Is sleep really for sissies? Understanding the role of work in insomnia in the US. Social Science and Medicine, 66, 715-726.

Hislop J. (2007) A bed of roses or a bed of thorns? Negotiating the couple relationship through sleep. Sociological Research Online. 12(5). Retrieved December 10, 2008, from http://www.socresonline.org.uk/12/5/2.html

Hislop J and Arber S. (2003) Sleepers Wake! The gendered nature of sleep disruption among mid-life women. Sociology, 37, 695-711.

Hislop J and Arber S. (2006) Sleep, gender and aging. In TM Calsanti and KL Slevin. eds. Age Matters: Realigning Feminist Thinking. Pp 225-246. Routledge, New York.

Jenkins CD, Stanton BA, Niemcryk SJ and Rose RM. (1988) A scale for the estimation of sleep problems in clinical research. Journal Clinical Epidemiology, 41, 313-321.

Kenny DA and Cook W. (1999) Partner effects in relationship research: Conceptual issues, analytic difficulties, and illustrations. Personal Relationships, 6, 433-448.

Lallukka T, Arber S, Rahkonen, $\mathrm{O}$ and Lahelma E. (2010) Complaints of insomnia among midlife employed people - the contribution of childhood and present socio-economic circumstances, Sleep Medicine, $11,828-836$. 
Lallukka T, Dregan A and Armstrong D. (2011) Comparison of a Sleep Item From the General Health Questionnaire-12 With the Jenkins Sleep Questionnaire as Measures of Sleep Disturbance. Journal of Epidemiology, 21, 474-80.

Linton SJ. (2004) Does work stress predict insomnia? A prospective study. British Journal of Health Psychology, 9, 127-136.

Marmot M. (2010) Foreword. In F Cappaccio, M Miller and S Lockley. eds. Sleep, Health and Society. From Aetiology to Public Health. Pp v-vi. Oxford University Press, Oxford.

McFall S and Garrington N. eds. (2011) Understanding Society: Early findings from the first wave of the UK's Household Survey. The Institute for Social Research, Colchester, Essex.

Meadows R, Arber S, Venn S and Hislop J. (2008) Unruly bodies and couples' sleep. Body \& Society 14, 75-92.

Rasbash J, Steele F, Browne WJ and Prosser B. (2005) A Users guide to MLwiN version 2.0. University of Bristol, Bristol.

Troxel WM, Buysse DJ, Hall M and Matthews KA. (2009) Marital Happiness and Sleep Disturbances in a MultiEthnic Sample of Middle-Aged Women. Behavioral Sleep Medicine, 7, 2-19.

Troxel WM, Buysse DJ, Matthews KA, Kravitz HM, Bromberger JT, Sowers MF and Hall M. (2010) Marital/Cohabitation Status and History in Relation to Sleep in Midlife Women. Sleep, 33, 973-81.

Venn S. (2007) It's okay for a man to snore: The influence of gender on sleep disruption in couples. Sociological Research Online. 12(5). Retrieved December 12, 2008 from http://www.socresonline.org.uk/12/5/1.html

Venn S, Arber S, Meadows R and Hislop J. (2008) The fourth shift: Exploring the gendered nature of sleep disruption in couples with children. British Journal of Sociology, 59, 79-97.

Vitiello MV, Moe KE and Prinz PN. (2002) Sleep complaints cosegregate with illness in older adults. Clinical research informed by and informing epidemiological studies of sleep. Journal of Psychosomatic Research, 53, 555-559.

Weich S. (2010) The epidemiology of sleep and depression. In F Cappaccio, M Miller and S Lockley. eds. Sleep Epidemiology. Pp 178-190. Oxford University Press, Oxford.

Whalley L. (2001) The ageing brain. Phoenix Books, London.

Williams SJ. (2005) Sleep and society: sociological ventures into the (un)known. Routledge, Abingdon.

Williams SJ and Boden S. (2004) Consumed with sleep? Dormant bodies in consumer culture. Sociological Research Online. 9:2 Retrieved December 10, 2008, from http://www.socresonline.org.uk/9/2/williams.html

Williams S, Meadows R and Arber S. (2010) The sociology of sleep. In F Cappaccio, M Miller and S Lockley. eds. Sleep, Health and Society. From Aetiology to Public Health. Pp 275-299. Oxford University Press, Oxford.

\section{Endnotes}

'As second order PQL is known to be biased, models were also run using MCMC estimation. Results were comparable. We report the PQL results in the paper to enable replication of analysis.

ii Wave 1 of Understanding Society also collected data on sleep medication use; asking how often respondents took any prescribed or over the counter medication in the past month to help them sleep. As our primary focus is on gender differences within self reports of sleep maintenance problems across different couple types, we do not include medication use in the models presented here. However, unreported analysis confirms that the odds ratios remain essentially of the same magnitude if sleep medication use is included in the models

iii Data were checked to examine whether there was a correlation between an individual's sleep maintenance and their answer to whether they 'wake through snoring'. A strong correlation could suggest a problem with including this in the models; as at the couple level both partners' sleep maintenance is being considered. Coefficients for the data set as a whole were 0.252 , which whilst significant $(p<0.05)$ suggests that it is not overly problematic to include 'partner reports of snoring' in the models.

iv This is not necessarily to suggest that partner behaviours are 'causing' nocturnal awakenings. As one of the reviewers usefully pointed out, those who spend more time awake for other reasons will be more likely to hear and report their partner snoring, even if it is relatively unobtrusive. Whilst we acknowledge this and are grateful that the reviewer requested that we clarify this point - it is interesting that the association is with partner reports of snoring (not individuals reporting that their partner snores). We also acknowledge that a person's own snoring can impact on their sleep. We did not include this in models as our focus was principally on gender difference in the social factors entered and the possible differences between younger and older couples. 